\title{
Calculation of crack stress density of cement base materials
}

\author{
Sui Chun-e $e^{1, *}$ \\ ${ }^{1}$ Transportation Institute, Inner Mongolia University, Inner Mongolia 010000, China
}

\begin{abstract}
In this paper, the fracture load of cement paste with different water cement ratio, different mineral admixtures, including fly ash, silica fume and slag, is obtained through experiments. the threedimensional fracture surface is reconstructed and the three-dimensional effective area of the fracture surface is calculated. the effective fracture stress density of different cement paste is obtained. The results show that the polynomial function can accurately describe the relationship between the three-dimensional total area and the tensile strength
\end{abstract}

\section{Introduction}

In recent years, the quantitative description of the geometric characteristics of fracture surface has become the research object of many people through various experimental methods and calculation methods. According to the role of various structures and external factors in the fracture process, it is a good method to establish the relationship between the geometric characteristics of fracture surface and material properties, and to calculate the fracture stress. So far, however, most of the analysis has been directed to planar analysis. According to the analysis of the occurrence and extension of cracks and other related factors, there are some problems in the study of three-dimensional effective fracture stress according to the plane characteristics $[4,5]$.

According to the different water cement ratio and tensile strength of cement paste with different mineral admixtures, the three-dimensional effective area of crack surface is reconstructed and the effective crack stress of different cement paste is calculated.

\section{Test}

\subsection{Materials}

The cement used in the study was type I/II Portland cement with fineness $381 \mathrm{~m}^{2} / \mathrm{kg}$. 28d flexural strength of the samples was $7.5 \mathrm{MPa}$. Fly ash (FA) with apparent density of $2.2 \mathrm{~g} / \mathrm{cm}^{3}$ was used, and it is a low-calcium ash with fineness $454 \mathrm{~m}^{2} / \mathrm{kg}$. The fineness of silica fume (SF) was about $20000 \mathrm{~m}^{2} / \mathrm{kg}$. Ground blast furnace slag (GBFS) with fineness of $740 \mathrm{~m}^{2} / \mathrm{kg}$ and apparent density of $2.88 \mathrm{~g} / \mathrm{cm}^{3}$ was used

\subsection{Test mixture ratio}

\footnotetext{
* Corresponding author: sce2008_tl@,163.com
}

Controlling the water cement ratio of the cement slurry to be 0.3 and 0.35 respectively; The mixed materials are fly ash, ground slag and silica fume respectively, and the content of the mixed materials is $15 \%, 25 \%$ and $5 \%$ of the total amount of the cementing materials respectively. The mix design is shown in table 1 .

Table 1. Mix designs of cement mixtures prepared.

\begin{tabular}{|l|l|l|l|l|l|l|l|}
\hline $\begin{array}{l}\text { Seri } \\
\text { es }\end{array}$ & Mix & $\begin{array}{l}\text { W/ } \\
\text { B }\end{array}$ & C(g) & $\begin{array}{l}\text { W } \\
(\mathrm{g})\end{array}$ & $\begin{array}{l}\text { FA } \\
(\mathrm{g})\end{array}$ & $\begin{array}{l}\text { GB } \\
\text { FS( } \\
\mathrm{g})\end{array}$ & $\begin{array}{l}\text { SF } \\
(\mathrm{g})\end{array}$ \\
\hline A1 & $\begin{array}{l}\text { Contro } \\
1\end{array}$ & 0.3 & 2600 & 780 & 0 & 0 & 0 \\
\hline A2 & $\begin{array}{l}\text { Contro } \\
1\end{array}$ & $\begin{array}{l}0.3 \\
5\end{array}$ & 2600 & 910 & 0 & 0 & 0 \\
\hline B1 & $\begin{array}{l}15 \% \\
\text { FA }\end{array}$ & 0.3 & 2210 & 780 & 390 & 0 & 0 \\
\hline B2 & $\begin{array}{l}15 \% \\
\text { FA }\end{array}$ & $\begin{array}{l}0.3 \\
5\end{array}$ & 2210 & 910 & 390 & 0 & 0 \\
\hline C1 & $\begin{array}{l}25 \% \\
\text { GBFS }\end{array}$ & 0.3 & 1950 & 780 & 0 & 650 & 0 \\
\hline C2 & $\begin{array}{l}25 \% \\
\text { GBFS }\end{array}$ & $\begin{array}{l}0.3 \\
5\end{array}$ & 1950 & 910 & 0 & 650 & 0 \\
\hline D1 & $5 \%$ SF & 0.3 & 2470 & 780 & 0 & 0 & $\begin{array}{l}13 \\
0\end{array}$ \\
\hline D2 & $5 \%$ SF & $\begin{array}{l}0.3 \\
5\end{array} 2470$ & 910 & 0 & 0 & $\begin{array}{l}13 \\
0\end{array}$ \\
\hline
\end{tabular}

\subsection{Test methods}

The specimen is $40 \times 40 \times 160 \mathrm{~mm}$, after being demoulded the specimens are put into water for curing to test age, the curing temperature is $(20 \pm 2)^{\circ} \mathrm{C}$, Then the following tests are carried out: firstly, the tensile strength of each group of test pieces is measured, and the average value is taken; Protect section well, using KEYENCE super depth of field three-dimensional micro system to shape the fracture surface of each specimen three-dimensional morphology, and through the mathematical method to calculate the effective cross-sectional area of fracture 
surface of tensile fracture specimen, finally combined with tensile strength to calculate the effective cracking stress of different cement paste was broken, the threedimensional total area and tensile strength according to polynomial function, linear function, logarithmic function, power function and exponential function fitting regression analysis, comparative analysis. The KEYENCE ultra-depth-of-field three-dimensional microscopic system is as shown in figure 1 .

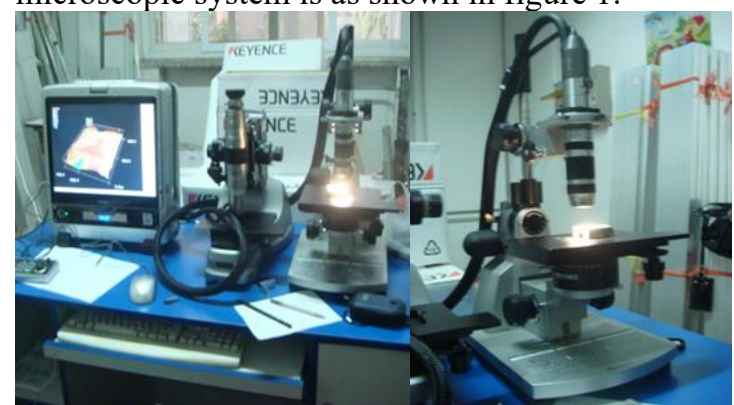

Fig.1. KEYENCE ultra-depth three-dimensional microscopy system

\section{Test results and analysis}

\subsection{The tensile strength of each group of specimens is shown in table 2.}

Table 2. Tensile strength

\begin{tabular}{|c|cccccccc|}
\hline $\begin{array}{c}\text { Specimen } \\
\text { number }\end{array}$ & A1 & A2 & B1 & B2 & C1 & C2 & D1 & D2 \\
\hline $\begin{array}{c}\text { Tensile } \\
\text { strength(Mpa) }\end{array}$ & 3.6 & 3.2 & 2.53 & 2.48 & 2.84 & 2.65 & 2.3 \\
& \multicolumn{6}{|c|}{2.2} & & \\
\hline
\end{tabular}

\subsection{Three - dimensional morphology of fracture surface of remolded specimen}

The actual morphology of the fracture surface of the $\mathrm{C} 1$ sample is shown in figure 2. The three-dimensional morphology of the fracture surface of the specimen was modeled by KEYENCE, as shown in figure 3. Because the use of this instrument has the requirement of depth of field range, the overall section area of the test is relatively large, and the surface of the concave and convex condition is relatively small, so the observation will be a specimen section is divided into four parts, each part of the measured area is the effective section area of the cross section. Figure 4 shows a processed three-dimensional sectional perspective view

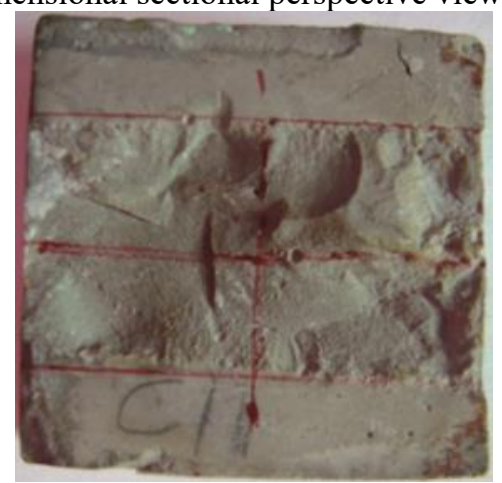

Fig. 2. The actual morphology of fracture surfaces of $\mathrm{C} 1$

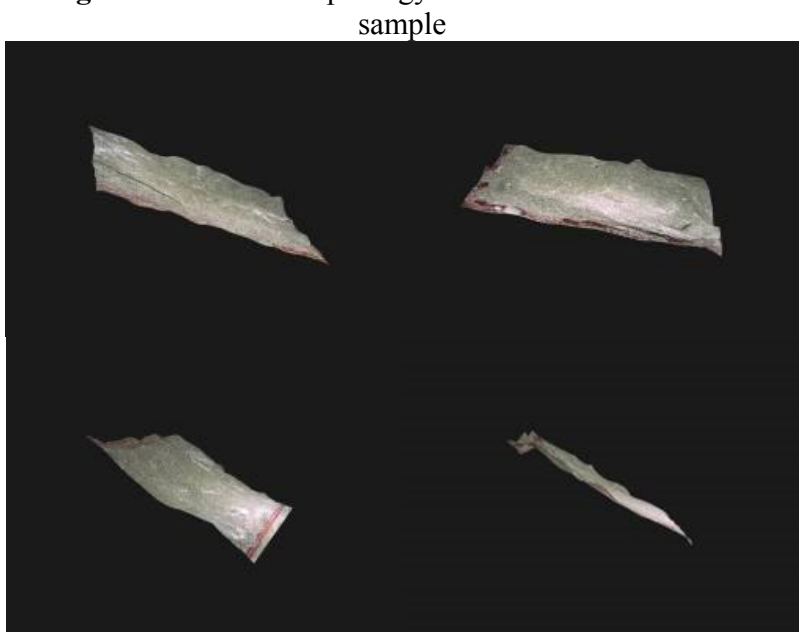

Fig. 3. The stereoscopic pattern of the four sections of $\mathrm{C} 1$

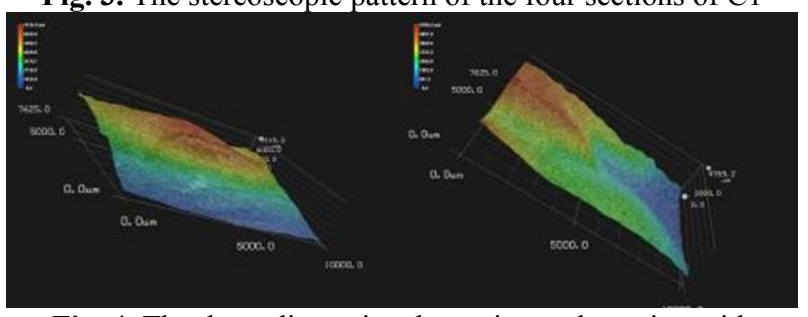

Fig. 4. The three-dimensional map in crack section with elevation

\subsection{Calculation of three-dimensional effective cross-sectional area of tensile test piece}

Due to the requirements of the depth of field of the test instrument, and in order to improve the test accuracy, each $40 \mathrm{~mm}$ x $40 \mathrm{~mm}$ interface is divided into eight partitions as shown in Fig. 5, the plane area of each partition is $10 \mathrm{~mm} \times 10 \mathrm{~mm}=100 \mathrm{~mm}$. Ten elevation difference curves are measured from top to bottom in each partition, and the length of any curve is calculated by using Fotran language and principle of calculus. Assuming that the width of each curve is $1 \mathrm{~mm}$, the three-dimensional effective fracture area of this part is $\mathrm{A} 1=\mathrm{s} \times 1 \mathrm{~mm} \times 10$, and the three-dimensional effective area of section a1 is $\mathrm{A}=\mathrm{A} 1+\mathrm{A} 2+\ldots+\mathrm{A} 8$.

The three-dimensional effective cross-sectional area of A1 is calculated using the above method and is shown in table 3 . Table 4 lists the three-dimensional effective cross-sectional area of all specimens.

\begin{tabular}{|c|c|c|c|}
\hline \multicolumn{5}{|c|}{ Reserved crack } \\
\hline 1 & 2 & 3 & 4 \\
\hline 5 & 6 & 7 & 8 \\
\hline \multicolumn{4}{|c|}{ Reserved crack } \\
\hline
\end{tabular}

Fig. 5. Schematic diagram of cross-section division of A1

Table 3. Effective cross-sectional area of A1

\begin{tabular}{|l|l|l|l|}
\hline $\begin{array}{l}\text { Name of } \\
\text { each part }\end{array}$ & $\begin{array}{l}\text { Area per } \\
\text { partition } \\
\left(\mathrm{mm}^{2}\right)\end{array}$ & $\begin{array}{l}\text { Three }- \text { dimensional } \\
\text { total area }\left(\mathrm{mm}^{2}\right)\end{array}$ & $\begin{array}{l}\text { Total area } \\
\text { of plane } \\
\left(\mathrm{mm}^{2}\right)\end{array}$ \\
\hline
\end{tabular}




\begin{tabular}{|c|c|c|c|}
\hline 1 & 368.381 & \multirow{8}{*}{2541.644} & \multirow{8}{*}{800} \\
\hline 2 & 347.838 & & \\
\hline 3 & 314.061 & & \\
\hline 4 & 225.863 & & \\
\hline 5 & 218.479 & & \\
\hline 6 & 493.138 & & \\
\hline 7 & 246.195 & & \\
\hline 8 & 327.688 & & \\
\hline
\end{tabular}

Table 4. Effective cross-sectional area of A1

\begin{tabular}{|l|l|l|l|}
\hline $\begin{array}{l}\text { Specimen } \\
\text { number }\end{array}$ & $\begin{array}{l}\text { Tensile } \\
\text { strength } \\
(\mathrm{Mpa})\end{array}$ & $\begin{array}{l}\text { Three - dimensional } \\
\text { total } \\
\text { area }\left(\mathrm{mm}^{2}\right)\end{array}$ & $\begin{array}{l}\text { Cracking } \\
\text { stress } \\
\text { density(Mpa/ } \\
\left.\mathrm{mm}^{2}\right)\end{array}$ \\
\hline A1 & 3.6 & 2541.644 & $1.42 \mathrm{E}-03$ \\
\hline A2 & 3.2 & 2202.400 & $1.45 \mathrm{E}-03$ \\
\hline B1 & 2.53 & 2123.390 & $1.19 \mathrm{E}-03$ \\
\hline B2 & 2.48 & 2230.400 & $1.11 \mathrm{E}-03$ \\
\hline C1 & 2.84 & 2073.750 & $1.37 \mathrm{E}-03$ \\
\hline C2 & 2.65 & 2000.000 & $1.33 \mathrm{E}-03$ \\
\hline D1 & 2.3 & 2858.610 & $8.05 \mathrm{E}-04$ \\
\hline D2 & 2.2 & 3004.800 & $7.32 \mathrm{E}-04$ \\
\hline
\end{tabular}

\subsection{Analysis of the relationship between the three-dimensions total area and tensile strength}

According to polynomial function, linear function, logarithmic function, power function and exponential function, the tensile strength and the total area of fracture surface were fitted and regressed respectively, and the results are compared and analyzed.

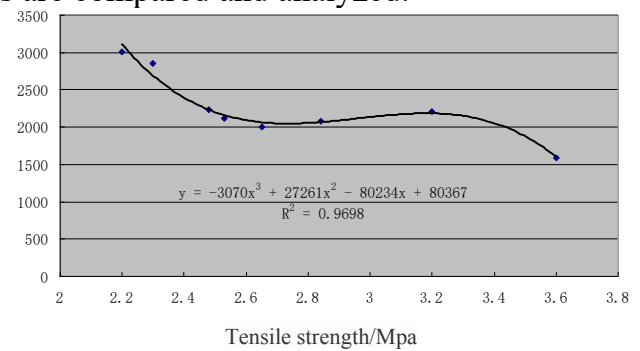

Fig. 6. The polynomial function relationship between threedimensional areas and tensile strength

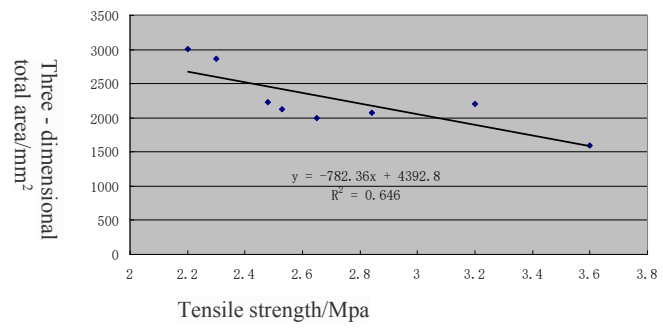

Fig. 7. The linear function relationship between threedimensional areas and tensile strength

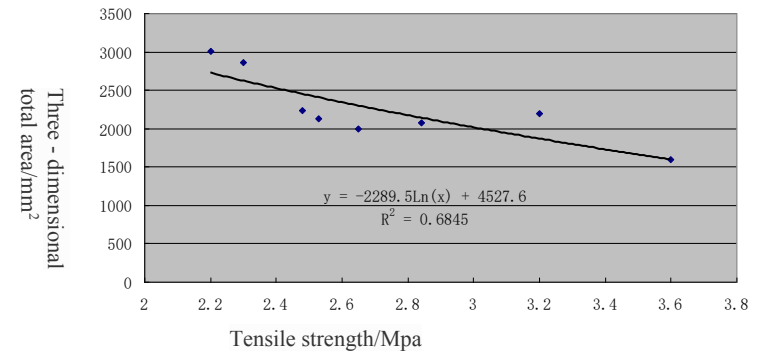

Fig. 8. The logarithmic function relationship between three-

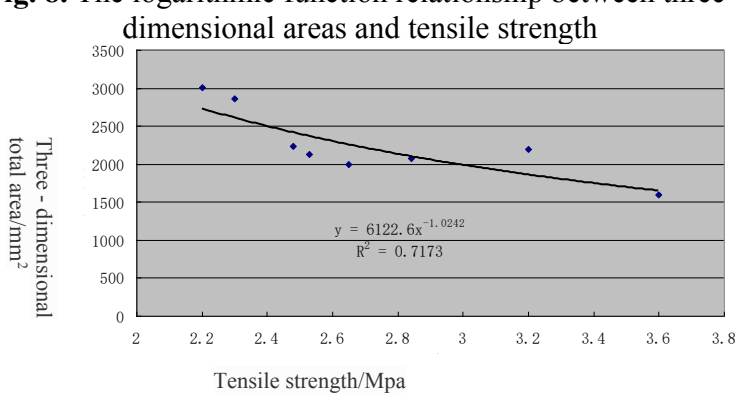

Fig. 9. The power function relationship between threedimensional areas and tensile strength

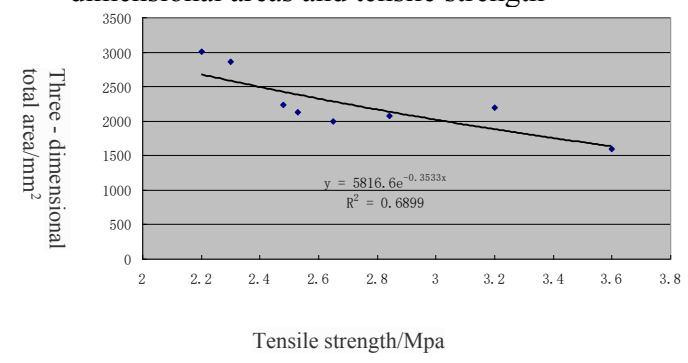

Fig. 10. The exponential function relationship between threedimensional areas and tensile strength

\section{Conclusions}

1) The three-dimensional morphology of fracture surfaces of different specimens can be formed by using KEYENCE ultra-depth-of-field three-dimensional micro-system; The three-dimensional effective area of tensile fracture specimen section can be calculated by mathematical method, and combined with tensile strength, the effective cracking stress of different cement pastes can be calculated. 2)Analysis and fitting regression the relationship between the three-dimensional total area and tensile strength by polynomial function, linear function, logarithmic function, power function and exponential function, it can be found that the polynomial function fitting effect is the best, its correlation coefficient is the largest.

\section{Acknowledgements}

Authors wishing to acknowledge the financial support provided by Inner Mongolia autonomous region natural science foundation project(2015BS0505).

\section{References}


1. Coster M and Chermant JL. Recent developments inquantitative fractog raphy. I nt Metals Rev. 28 228-250 (1983)

2. Zhu P, Chen B and Tang W. Three dimensional topography reconstruction and quanti tative analysis of metallic fracture surfaces.Chi. J. of Stereology and image analysis. 2 1-5(1997)
3. Pentland A. Shape information from shading:A theory about human perception. Proc. Intl. Conf.CV.TAMPA.404-413 ()1988

4. Zen $\mathrm{C}$ and Der-Baau Perng. Automatic reconstruction of 3-D solid objects from 2-D orthographic. Patten Recogition. 21 155-162(1988)

5. Kimmel R and Bruckatein A M. Goble shape from shading. CVIU. 62 360-369(1995) 